\title{
Correlations between Axial and Oblique Loaded Column
}

\author{
Salwani Mohd Salleh ${ }^{1}$, Barkawi Sahari ${ }^{2}$, Aidy Ali $^{3}$, Mas Ayu Hassan ${ }^{1}$, and Rosdi Daud ${ }^{1}$ \\ ${ }^{1}$ Faculty of Mechanical Engineering, Universiti Malaysia Pahang, 26600 Pekan, Pahang. \\ ${ }^{2}$ Department of Mechanical and Manufacturing Engineering, Faculty of Engineering, Universiti Putra Malaysia, 43400 Serdang, Selangor \\ ${ }^{3}$ Department of Mechanical Engineering, Faculty of Engineering, Universiti Pertahanan Nasional Malaysia, Kem Sungai Besi, 57000 Kuala \\ Lumpur.
}

\begin{abstract}
In an impact, a structure is rarely subjected to pure axially loading. Load endured by an axially loaded column has been analytically derived by previous researchers, whereas it is very limited works on predicting the obliquely loaded column performance. In this study, the force response curve of the obliquely loaded empty aluminum column is analyzed and compared to its axially loaded column. Theoretical formula to calculate the axial mean force has been applied to obliquely loaded column, and it has yields a largely deviated value. Thus, a modified equation to cater for obliquely loaded column has been proposed.
\end{abstract}

\section{Introduction}

The recent trend in automobile design is aimed at improving crash safety. For the crash safety, energy absorbing members have to absorb sufficient collision energy. Automotive structures are designed to sustain impact loading in diverse crash directions such as frontal, lateral and rear impact. Above all crash events, frontal collision was identified as the most common accidents on the road and gives rise to high portion of death [1-2]. Thus, it is vital to have an efficient energy absorbing structure on the front side of an automobile. The main energy absorber on the front side of automotive body is crash box and longitudinal members that commonly represented by column.

The threat to passenger safety arouses the need for the crash test. In accordance with the safety requirement, Federal Motor Vehicle Safety Standard (FMVSS) No. 208 has set a procedure for a frontal rigid barrier test of up to $48 \mathrm{kmph}$, at angles from the perpendicular $(90$ degrees) to the line of travel of up to 30 degrees [3]. It has been a current practice to initiate crash testing with simulation to avoid expensive investment on repeated physical testing. Due to the rapid development in the computational capabilities, simulation is well accepted by the as a way to reduce cost associated with physical test of preliminary design. Numerous research works has been presented on structure subjected to axial and bending [4-7], whereas a very limited study has been conducted on theoretical equation for oblique loading. This study will propose improvised axially loaded equation to predict the mean force of the obliquely loaded column based on simulation.

\section{Theoretical Background}

Crashworthiness parameters are used to assess the performance of energy absorber structure. A good crashworthiness structure can absorb high energy in a controlled manner and yet the forces experiences during collapse do not exceed the allowable range. The primary data usually extracted from a crushing test is the loaddisplacement curve. Typical load-displacement curve for a thin-walled structure is shown in Fig. 1.

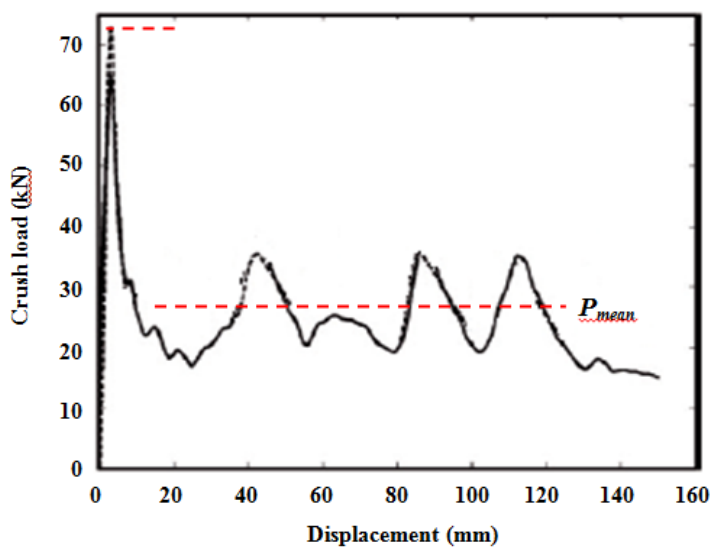

Figure 1. Typical force-displacement curve for axial loading

The mean load, $\mathrm{P}_{\text {mean }}$ is a parameter commonly used to calculate the energy absorbing capability of a structure. Generally, it is defined as [8]:

$$
P_{\text {mean }}=\frac{E_{a}}{\delta}
$$


where is the total energy absorbed during collapse and represents displacement. According to Wierzbicki and Abramowicz [7], the mean crushing force of axially loaded square tube can be calculated by

$$
P_{\text {mean }, A}=13.06 \sigma_{0} \cdot w_{m}^{1 / 3} t^{5 / 3}
$$

where $\boldsymbol{\sigma}_{\mathbf{0}}$ is the characteristics stress taken as

$$
\sigma_{0}=\frac{\sigma_{0.2}+\sigma_{u}}{2}
$$

$\boldsymbol{\sigma}_{\mathbf{0 . 2}}$ is the stress at $0.2 \%$ plastic strain, is the ultimate stress and is the mean width defined as

$$
w_{m}=w-t
$$

$t$ is the column thickness and $\mathrm{w}$ is the outer column width.

\section{Methodology}

\subsection{Validation}

Fig. 2 shows the deformation pattern for both experimental and simulation. The simulated crushed empty column is deformed in the same manner as in the experiment.

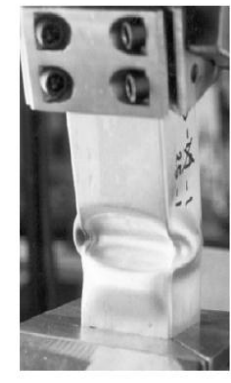

(a)

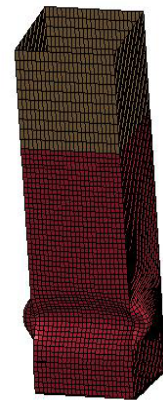

(b)
Figure 2. Deformation of empty column subjected to 5 degrees loading angle (a) experimental [9] and (b) simulation

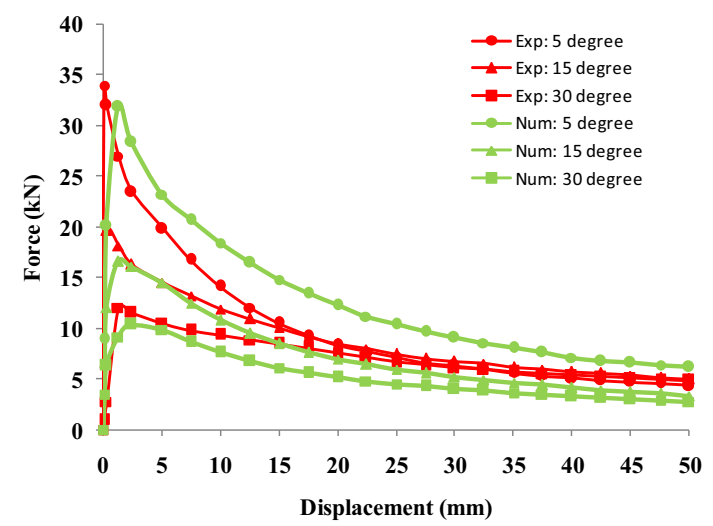

Figure 3. Force-displacement curve comparison between experimental and simulation
Fig. 3 compares quasi-static simulation of aluminum column subjected to oblique loading to the experimental work done by previous researcher. Good agreement between the simulation and experimental result is obtained.

\subsection{Finite element analysis}

In this study, the model is drawn using the CATIA and meshed by using Hypermesh. The keywords file is then imported into Ls-Dyna. Fig. 4 shows mesh of the square column and direction of load during impact.

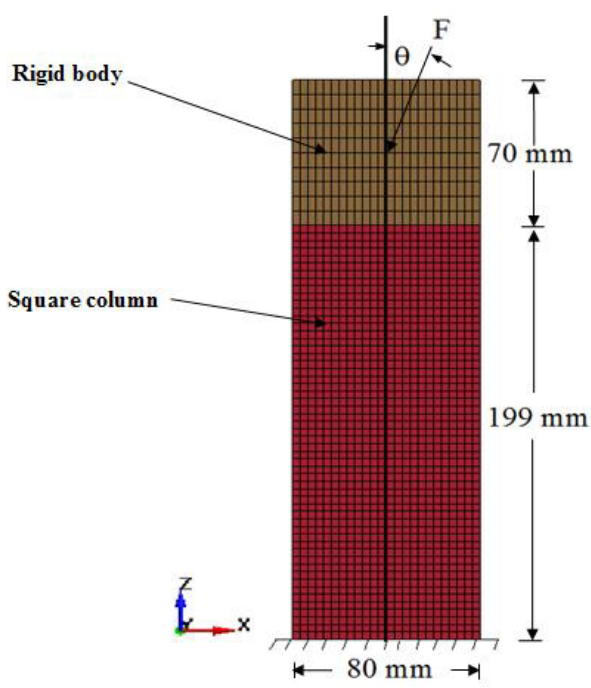

Figure 4. direction of load during impact

The square column and the automotive side member are modeled using shell elements in LS-Dyna. There is a broad library of material models available in LS-Dyna. The material model type 24 [PIECEWISE LINEAR PLASTICITY] is used to model the behavior of aluminum alloy under impact. A stress versus strain curve is defined for this elasto-plastic aluminum alloy. Aluminum alloy used in this study is AA6060, temper T4. Table1 summarizes the mechanical properties of AA6060 T4. The important properties are the density, $\rho$; Young's modulus, E; Poisson ratio, v; yield stress, $\sigma_{\mathbf{y}}$; ultimate tensile stress, $\sigma_{\mathbf{u}}$ and fracture strain, \&f.

Table 1. Mechanical properties of AA6060 T4 [10]

\begin{tabular}{|c|c|c|c|c|c|c|}
\hline Material & $\begin{array}{c}\boldsymbol{\rho} \\
\left(\mathbf{k g} / \mathbf{m}^{\mathbf{3}}\right)\end{array}$ & $\begin{array}{c}\mathbf{E} \\
\left(\mathbf{N} / \mathbf{m m}^{\mathbf{2}}\right)\end{array}$ & $\boldsymbol{v}$ & $\begin{array}{c}\boldsymbol{\sigma}_{\mathbf{y}} \\
\left(\mathbf{N} / \mathbf{m m}^{\mathbf{2}}\right)\end{array}$ & $\begin{array}{c}\boldsymbol{\sigma}_{\mathbf{u}} \\
\left(\mathbf{N} / \mathbf{m m}^{\mathbf{2}}\right)\end{array}$ & $\boldsymbol{\varepsilon}_{\mathbf{f}}$ \\
\hline AA6060 & 2700 & 66820 & 0.28 & 91 & 175 & 0.22 \\
\hline
\end{tabular}

In the dynamic simulation, the square column is subjected to oblique loading for an angle between 5 to 30 degrees as shown in figure 3.2 . A velocity of $48 \mathrm{~km} / \mathrm{hr}$ as indicated in the frontal barrier crash test in fmvss no. 208 is prescribed to the rigid body. 


\section{Result and Discussions}

Fig. 5 plots the correlation between the numerical and theoretical results. The straight line indicates the unity between the numerical and theoretical values. Theoretical values are calculated based on equation (2). It can be seen that the theoretical model over-predicted the Pmean values.

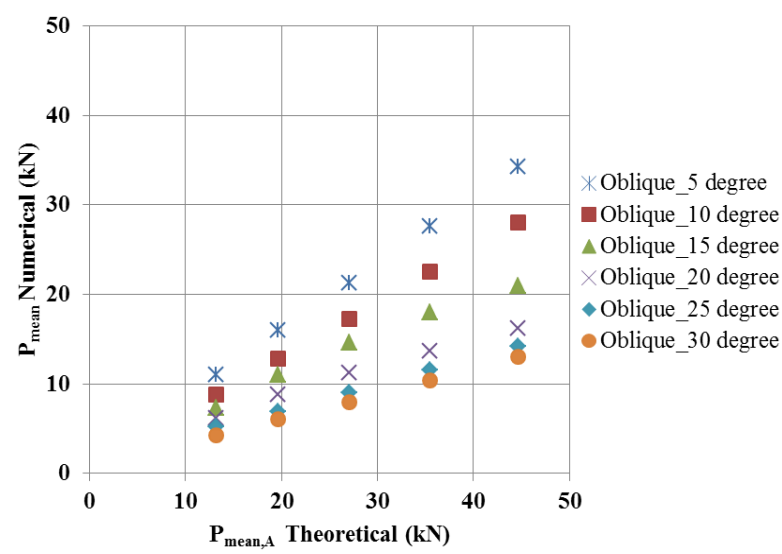

Figure 5. Correlation between results obtained from numerical and theoretical

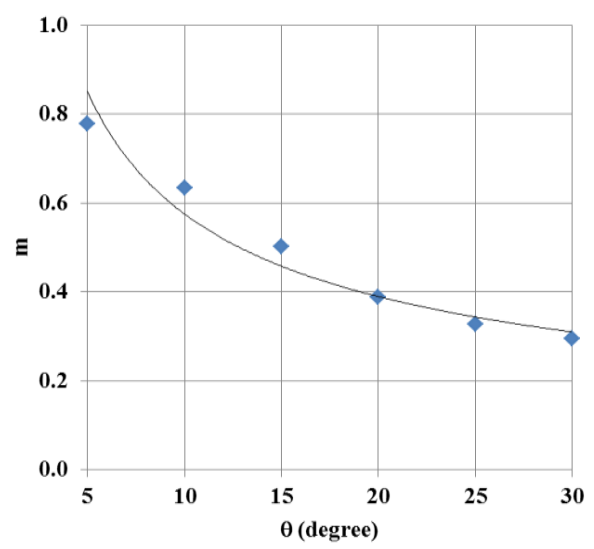

Figure 6. Slopes of various loading angles

It is understandable since equation (2) is meant for axially loaded column. Axially loaded column commonly failed under progressive buckling, absorbing more energy, $\mathrm{Ea}$ and yielding a higher Pmean values. Whereas, obliquely loaded column is commonly associated with local bending, reducing the energy absorption capability, Ea and causing a lower Pmean values.

Fig. 5 suggests that Pmean,A for theoretical of different loading angle can be shifted to its numerical values by introducing an equivalent factor, Ef.

By setting an intercept of zero, fitting lines are drawn for each loading angles, $\theta$ in Figure 6. The slope, $m$, obtained from Fig. 4 is plotted in Fig. 6.

Thus, the power law equivalent factor, Ef generated from Fig.6 is

$$
E_{f}=2.106 \cdot \theta^{-0.56}
$$

where $\theta$ is the loading angle. In order to better predict the mean force for obliquely loaded column, this study proposes a modified equation of the axial mean force, Pmean,A to incorporate the loading angle associated with oblique loading. The oblique mean load is defined as

$$
P_{\text {mean }, O}=13.06 \cdot E_{f} \cdot \sigma_{0} \cdot t^{2} \cdot\left(\frac{w_{m}}{t}\right)^{1 / 3}
$$

Fig. 7 plots the correlation between the numerical and theoretical results. The theoretical values are calculated based on equation (6). It can be seen that the modified equation improves the prediction of obliquely loaded column.

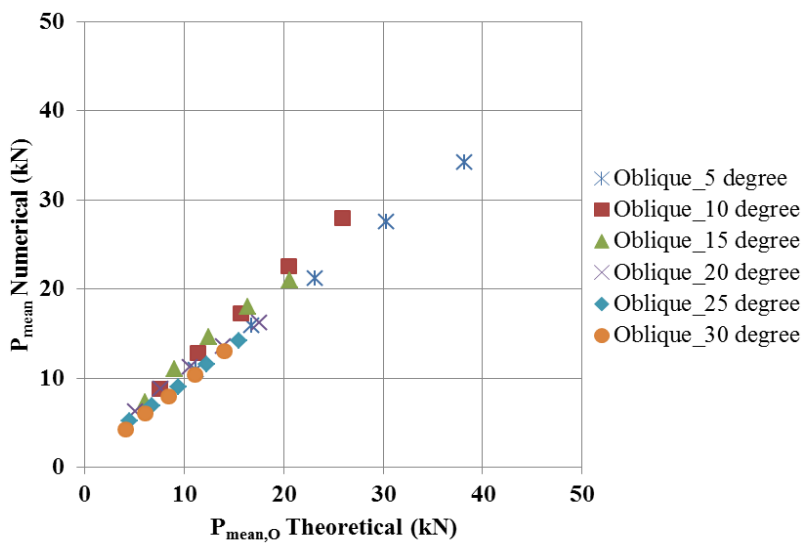

Figure 7. Correlation between results obtained from numerical and theoretical

\section{Conclusion}

Theoretical formula to calculate the axial mean force has been applied to obliquely loaded column, and it has yields a largely deviated value. Thus, a modified equation to cater for obliquely loaded column has been proposed as:

$$
P_{\text {mean }, O}=13.06 \cdot E_{f} \cdot \sigma_{0} \cdot t^{2} \cdot\left(\frac{w_{m}}{t}\right)^{1 / 3}
$$

\section{Acknowledgement}

The authors would like to thank Universiti Malaysia Pahang (UMP) for financial support on publication under RDU1303114.

\section{References}

1. Kokkula, S., Hopperstad, O. S., Lademo, O. G., Berstad, T., and Langseth, M. (2006). Offset impact behaviour of bumper beamâ€"longitudinal systems: 
numerical simulations. International Journal of Crashworthiness, 11(4), 317 - 336.

2. Kokkula, S., Langseth, M., Hopperstad, O. S., and Lademo, O. G. (2006). Offset impact behaviour of bumper beamâ€"longitudinal systems: experimental investigations. International Journal of Crashworthiness, 11(4), 299 - 316.

3. Hollowell, W. T., Gabler, H. C., Stucki, S. L., Summers, S., and James R. Hackney, N. (1999). Updated review of Potential Test Procedures for FMVSS No. 208: National Highway Traffic Safety Administration (NHTSA)o. Document Number)X.

4. M. S. Salwani, B. B. Sahari, Aidy Ali and A. A. Nuraini, The effect of automotive side member filling on car frontal impact performance, Journal of Mechanical Engineering and Sciences, 6 (2014) 873-880.

5. Zhang, Z. Wen, H. Zhang, Axial crushing and optimal design of square tubes with graded thickness, Thin Wall Struct, 84 (2014), pp. 263-274.
6. X. Zhang, H. Zhang, Axial crushing of circular multi-cell columns, Int J Impact Eng, 65 (2014), pp. 110-125.

7. R. Mohammad Javad and J. Ali, Effect of initiator, design, and material on crashworthiness performance of thin-walled cylindrical tubes: A primary multicriteria analysis in lightweight design, Thin-Walled Structures 96 (2015) 169-182.

8. W. Abramowicz and N. Jones, Dynamic progressive buckling of circular and square tubes. International Journal of Impact Engineering, 4(4) (1986) 243-270.

9. Reyes, M. Langseth and O.S. Hopperstad, Crashworthiness of aluminum extrusions subjected to oblique loading: experiments and numerical analyses. International Journal of Mechanical Sciences, 44(9) (2002) 1965-1984.

10. Reyes, M. Langseth and O.S. Hopperstad, Square aluminum tubes subjected to oblique loading. International Journal of Impact Engineering, 28(10) (2003) 1077-1106. 